\title{
A CLIMATOLOGIA VOLTADA ÀS ATIVIDADES AERONÁUTICAS
}

\author{
Edson Cabral ${ }^{1}$
}

\begin{abstract}
RESUMO
Este artigo mostra de que formas o geógrafo pode auxiliar, com seu conhecimento integrado dos vários elementos do meio, com as diversas aplicações da Climatologia Aeronáutica, desde a participação em uma equipe multidisciplinar de um Estudo de Avaliação de Impacto Ambiental ou no próprio dimensionamento de um aeroporto, na análise climatológica subsidiando uma previsão do tempo mais acurada, com a melhoria de modelos e prognósticos para a aviação, ou ainda, colaborando com estudos climatológicos, a partir de registros de aeroportos, com vários segmentos da sociedade, como empresas de abastecimento de água e energia elétrica, companhias petrolíferas, mineradoras, seguradoras dentre outras.
\end{abstract}

Palavras chave: Climatologia, climatologia aplicada, climatologia aeronáutica.

\section{LA CLIMATOLOGIA VOLTADA A LAS ACTIVIDADES AERONAUTICAS}

\section{RESUMEN}

Este artículo muestra de qué formas el geógrafo puede contribuir en varios segmentos de la sociedad como empresas de abastecimiento de agua y energía eléctrica, compañías petrolíferas, de mineración, y de seguros, entre otras, con su conocimiento integrado de los diversos elementos del medio ambiente, en las diferentes aplicaciones de la Climatología Aeronáutica, desde la participación en planteles multidisciplinarios para Estudios de Evaluación de Impactos Ambientales, en proyectos de aeropuertos, en análisis climatológicos que subsidian previsiones del tiempo más precisas, en la mejora de modelos y pronósticos para la aviación, o incluso, colaborando en estudios climatológicos a partir de registros en aeropuertos.

Palabras clave: climatología, climatología aplicada, climatología aeronáutica.

1 Professor Doutor - PUC de São Paulo, Universidade Anhembi Morumbi e Faculdade de Ciências e Letras de Bragança Paulista - edsoncab@pucsp.br ecabral@anhembi.br. 


\section{Introdução}

Como profissional capacitado a analisar de forma integrada os vários elementos do meio e correlacioná-los com o estudo do clima, o geógrafo têm a possibilidade de interagir com inúmeros campos do conhecimento: turismo, agricultura, arquitetura, aviação, saúde dentre outros. O escopo principal deste artigo é mostrar como o geógrafo pode contribuir, por intermédio da climatologia, com um campo do conhecimento extremamente peculiar, no caso, a aviação e suas atividades correlatas, área de atuação na qual o autor vêm trabalhando desde 1987, seja no campo operacional, da pesquisa e ultimamente no ensino superior. O trabalho tentará expressar, de maneira objetiva, as formas nas quais a climatologia pode ser aplicada em relação às atividades aeronáuticas, de maneira a auxiliar os três pilares que sustentam a aviação: a segurança, a economia e o conforto. Ao se fazer um retrospecto geral dos trabalhos científicos e operacionais sobre a climatologia voltada às atividades aeronáuticas, chega-se à conclusão que ainda são escassas tais pesquisas (CABRAL, 2000, p. 3), podendo ser citados com destaque os trabalhos dos meteorologistas Villela (1984) e Oliveira (2002), e ainda mais raras quando se leva em consideração a atuação dos geógrafos. Além do autor deste trabalho, que têm efetuado estudos desde o final dos anos de 1980, podem ser destacadas duas monografias de conclusão de curso, apresentadas em 2002, junto ao Departamento de Geografia da USP (GUEDES, 2002) e ao Instituto de Estudos Geográficos da Universidade de Coimbra (COSTA, 2002), analisando, respectivamente, a climatologia de episódios de turbulência moderada e forte no Aeroporto de Congonhas e uma análise climatológica geral do Aeroporto Francisco Sá Carneiro, em Coimbra, Portugal.

\section{Áreas de aplicação}

A climatologia atua como um dos importantes itens na viabilização do projeto de construção de um aeroporto, em sua fase pré-operacional, fazendo parte dos Estudos de Avaliação de Impacto Ambiental e definindo quais alterações poderão ser produzidas em relação às condições atmosféricas, quando do pleno funcionamento do complexo aeroportuário. O conhecimento das características climáticas do sítio é fundamental para estimar os impactos ambientais que venham a ocorrer com o processo de construção e exploração do aeroporto, bem como a influência de alguns parâmetros meteorológicos quando de sua operação plena. O estudo do clima do local a ser instalado um aeroporto depende de séries as mais longas possíveis, definidas pela W.M.O. (World Meteorological Organization), a partir de inúmeros elementos meteorológicos: temperatura, ventos, umidade, precipitação, nebulosidade, visibilidade, pressão atmosférica etc. e, para sua obtenção, devem ser buscados os registros de estações meteorológicas representativas da respectiva área de análise.

Em relação aos parâmetros mais significativos para as análises prévias das caracterizações climáticas locais, tem-se inicialmente a temperatura 
do ar, que influencia sobremaneira as atividades humanas, a vegetação, a fauna etc. e faz parte das classificações climáticas de forma geral. Os registros de temperatura levam em consideração suas médias mensais, médias mensais das mínimas, médias mensais das máximas e valores mínimos e máximos absolutos mensais, além do período livre de geadas. A partir de tais valores, são estabelecidas as características térmicas sazonais. Outro elemento importante na análise é a precipitação, cujos cálculos levam em consideração sua média anual, média mensal, freqüência de dias anual e mensal de chuva, chuvisco, neve e granizo, máxima em 24 horas e freqüência anual e mensal de dias com precipitação maior ou igual a $10 \mathrm{~mm}$. Esses registros visam caracterizar o comportamento pluviométrico de uma área, possibilitando estudar particularmente os processos de infiltração e erosão hídrica. Outro parâmetro analisado é a umidade atmosférica, por meio de registros de umidade relativa, tensão de vapor, ponto de orvalho e umidade absoluta, que se relacionam com inúmeros outros processos físicos, como a nebulosidade, precipitação, visibilidade e temperatura.

Tabela 1. Período mínimo necessário para caracterizar climaticamente a área de estudo.

\begin{tabular}{lcccc}
\hline Elemento & Ilhas & Costas & $\begin{array}{c}\text { Planícies } \\
\text { continentais }\end{array}$ & Montanhas \\
\hline Temperatura & 10 & 15 & 15 & 25 \\
Umidade & 3 & 6 & 5 & 10 \\
Nebulosidade & 4 & 4 & 8 & 12 \\
Visibilidade & 5 & 5 & 5 & 8 \\
Precipitação & 25 & 40 & 40 & 50 \\
\hline
\end{tabular}

Fonte: W.M.O., citado por MOPU (1998, p. 35).

Os ventos, por seu turno, são analisados em relação à sua predominância, freqüência, direção e intensidade, percurso médio e ocorrência de rajadas. Esse parâmetro é a base da confecção de modelos de difusão atmosférica, devendo ser considerado não somente o vento em superfície, como também sua variação vertical e sazonal. As emissões de poluentes nas operações de aeronaves nos aeródromos podem ser bastante significativas, principalmente quando associadas a condições de tempo estável, ocasionando névoas e obstruindo sobremaneira a visibilidade. Devem ser levadas em consideração, portanto, quando da realização dos Estudos de Avaliação de Impacto Ambiental, as condições meteorológicas e do sítio do local a ser construído o aeroporto e seu entorno, bem como os prognósticos das condições de estabilidade atmosférica que influem na dispersão dos gases e substâncias contaminantes. Para tanto, são montadas matrizes de estabilidade atmosférica com registros de direção, velocidade e freqüência dos ventos, assim como de radiação solar pois, com o aquecimento das camadas mais próximas da superfície, podem surgir processos turbulentos que favoreçam a dispersão dos poluentes.

Para os Estudos de Avaliação de Impacto Ambiental devem também 
ser considerados os seguintes elementos meteorológicos: evapotranspiração potencial e real; insolação (horas de sol) e radiação solar; visibilidade, nebulosidade e freqüência de dias de nevoeiro, cujo fenômeno se relaciona com a estabilidade atmosférica. Além da importante questão dos impactos ambientais, que podem advir da construção de áreas aeroportuárias e de sua operação, os elementos climáticos também auxiliam no próprio dimensionamento de um aeroporto. Os ventos, por exemplo, a partir do traçado de um anemograma (figura 1), contendo suas velocidades e freqüências, tomando por base uma série de pelo menos cinco anos de registros e com um mínimo de oito observações diárias, servem para o cálculo do número de pistas necessárias, bem como sua orientação. Os valores extremos de intensidade de vento são importantes na avaliação dos efeitos em relação à segurança de edifícios e outras construções na área aeroportuária como hangares, auxílios de navegação entre outros.

Os valores de temperatura média do mês mais quente do ano, denominados de temperatura de referência, são a base para calcular o comprimento das pistas a serem construídas, visto que as aeronaves necessitam de extensões maiores de pista quando em situações de temperaturas mais elevadas, justamente pelo efeito de maior rarefação do ar e menor sustentação nos procedimentos de pouso e decolagem. Os registros de precipitação servirão para análise da drenagem, assim como os dados de gelo, neve, granizo, nevoeiros, névoas e de visibilidade baixa, auxiliarão nos cálculos de porcentagens de restrição meteorológica para as operações de pouso e decolagem.

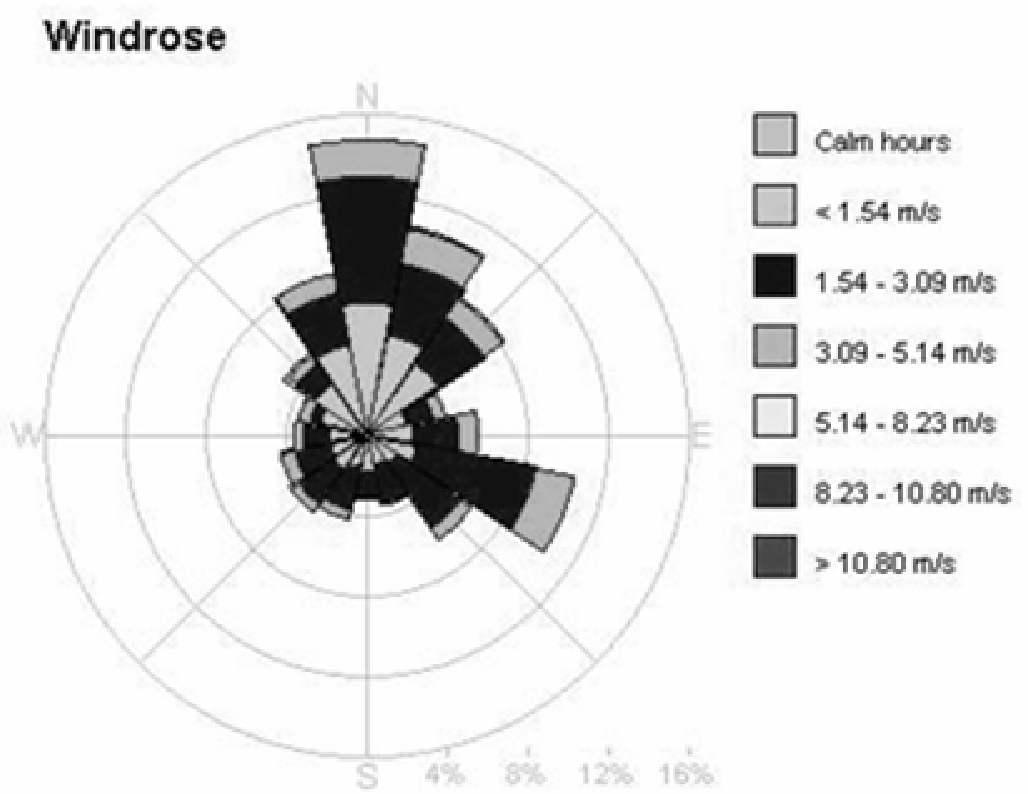

Figura 1. Modelo de anemograma

Fonte: EPA (2001). 
Outra importante área na qual o geógrafo pode dar sua contribuição nas atividades aeronáuticas é no tocante à pesquisas e estudos climatológicos abrangendo áreas de aeroportos, visando subsidiar, em última análise, a previsão do tempo, auxiliando na melhoria de modelos e prognósticos para a aviação. Estudos sobre a climatologia de fenômenos adversos (nevoeiros, trovoadas, turbulências, visibilidade e tetos baixos) requerem, dos estudiosos, além do embasamento técnico dos processos atmosféricos, também 0 conhecimento dos fatores geográficos locais. Análises realizadas para outros segmentos da sociedade, como empresas de abastecimento de água, energia elétrica, engenharia, companhias petrolíferas, mineradoras, construtoras e seguradoras, podem também ser feitas a partir dos registros climatológicos dos aeroportos, pois a maior parte deles conta com registros bastante fidedignos e com inúmeras estações meteorológicas operando diuturnamente, cobrindo todo o território brasileiro, incluindo todas as capitais dos estados e várias cidades de pequeno e médio portes.

\section{Os complexos aeroportuários e o clima}

As alterações que um aeroporto pode ocasionar em relação ao microclima e clima local são oriundas principalmente devido à construção de grandes superfícies pavimentadas e edificadas e a emissão, para a atmosfera, de partículas provenientes das atividades aeronáuticas. Em relação à escala microclimática, as alterações estão relacionadas particularmente à temperatura, à umidade e a formação de névoas. As pistas, hangares e áreas de espera de aeronaves de um aeroporto se constituem de grandes superfícies de concreto e asfalto sem vegetação e, conseqüentemente, expostas diretamente aos raios solares, fazendo com que as temperaturas sejam mais elevadas, no geral, em relação ao entorno do complexo aeroportuário, possibilitando o surgimento de processos de circulação de ar e movimentos turbulentos, associados e condicionados à topografia e ao meio circundante.

A título de ilustração, dois importantes Aeroportos Internacionais existentes na Região Metropolitana de São Paulo, Congonhas (figura 2), o que apresenta o maior número de movimentos (pousos e decolagens) do país e Guarulhos, o de maior número de passageiros, tiveram taxas de aumento de temperatura expressivas em décadas recentes (figura 3), vinculadas principalmente ao efeito de urbanização, o que têm contribuído sobremaneira com a forte diminuição dos nevoeiros, principalmente no Aeroporto de Guarulhos, resultando em uma melhoria significativa das condições operacionais daquele aeródromo, contribuindo para a segurança e a economia das operações aéreas (figura 4). Os nevoeiros no Aeroporto de Guarulhos tem sua origem ligada a fatores locais, de localização de seu sítio (acúmulo de ar frio na bacia, fontes de umidade - lagoas e vegetação no entorno) e conjugado aos sistemas meteorológicos atuantes na região, principalmente anticiclones, 0 mesmo podendo se inferir com relação ao fenômeno para o aeroporto de Congonhas, cuja gênese do fenômeno também está ligada à processos de perda radiativa noturna. 


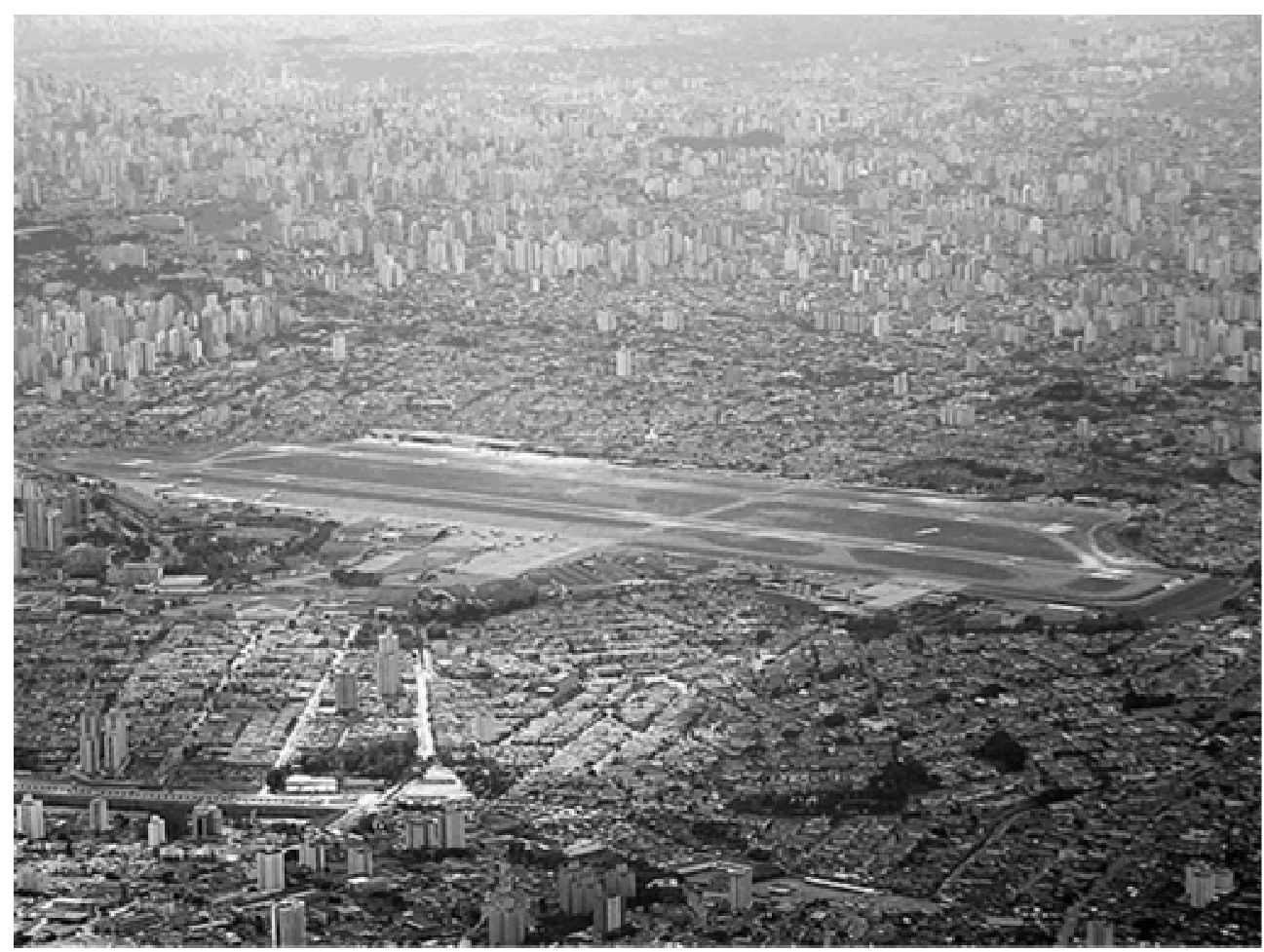

Figura 2. Vista aérea do Aeroporto de Congonhas.

Fonte: Kaufmann, G.

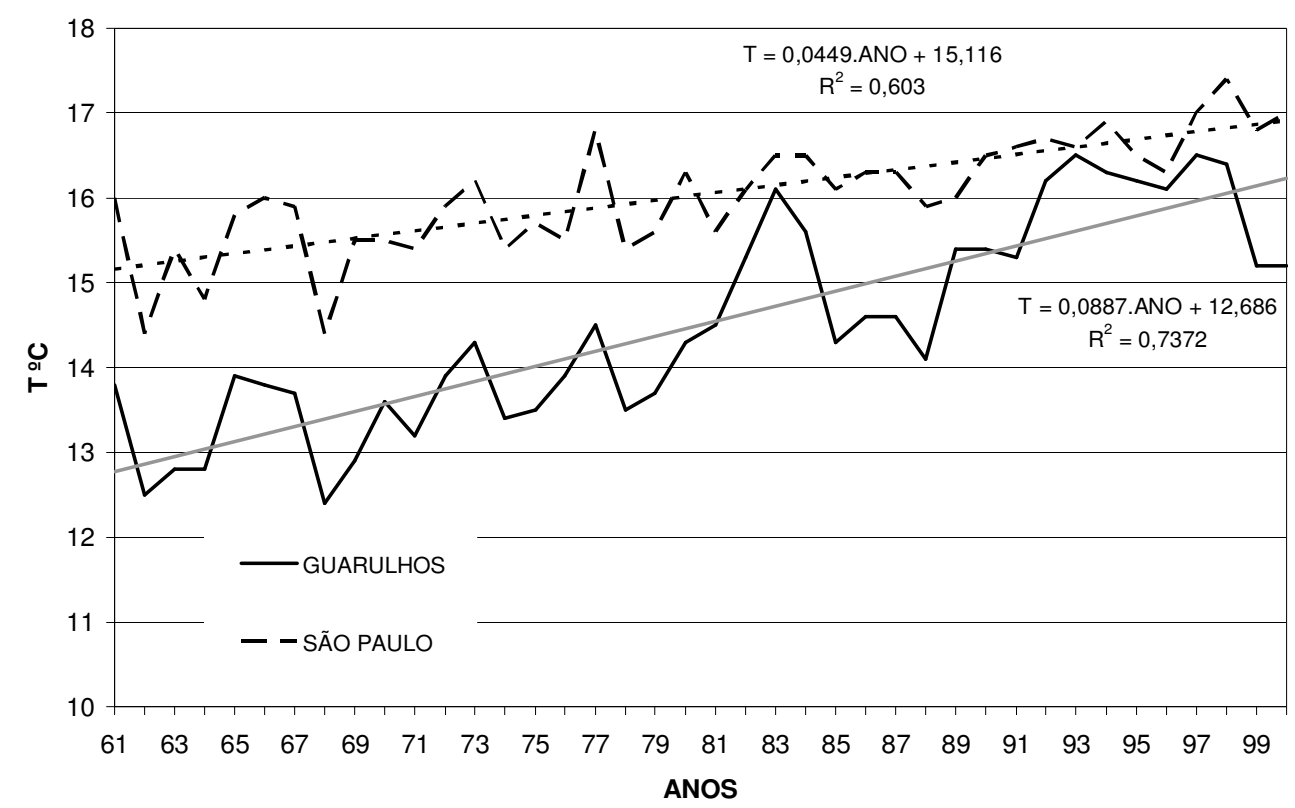

Figura 3. Comparativo de médias de temperaturas mínimas de Guarulhos e Congonhas (1961-2000).

Fonte: SRPV-SP (2001). 


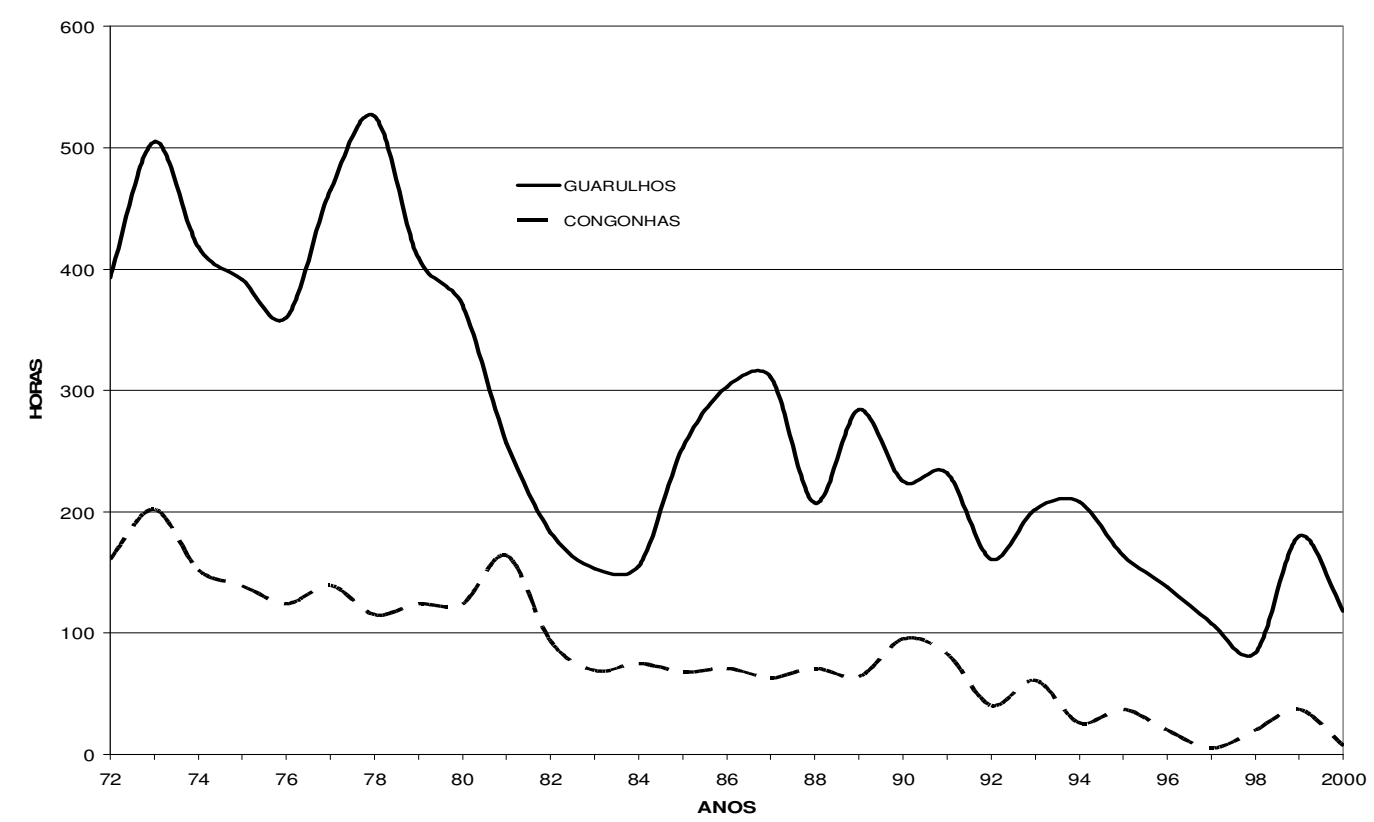

Figura 4. Comparativo de horas de nevoeiro - Guarulhos X Congonhas (1972-2000). Fonte: SRPV-SP (2001).

\section{Considerações finais}

São inúmeras as aplicações nas quais os geógrafos podem contribuir com seu conhecimento e experiência na área aeronáutica, seja na participação de uma equipe multidisciplinar visando a montagem de um Estudo de Avaliação de Impacto Ambiental, seja na análise climatológica fundamentando a previsão do tempo ou subsidiando, com estudos climatológicos a partir de registros de aeroportos, os vários segmentos da sociedade.

\section{ReferênciasBibliográficas}

CABRAL, E. A climatologia aeronáutica, suas aplicações e importância na sociedade, p.13, 2000, Rio de Janeiro. Anais...CD ROM do IV Simpósio Brasileiro de Climatologia Geográfica, 2000.

COSTA, P.M.A. Climatologia aeronáutica: o caso do Aeroporto Francisco Sá Carneiro. Coimbra, 2002. Monografia (Graduação em Geografia) - Instituto de Estudos Geográficos da Universidade de Coimbra.

GUEDES, F.D. Análise climatológica das ocorrências de turbulência moderada, turbulência forte ("wind shear") na área do Aeroporto Internacional de São Paulo (Congonhas). São Paulo, 2002. Trabalho de Graduação Individual, Departamento de Geografia da Universidade de São Paulo.

MOPU. Guías metodológicas para la elaboración de estudios de impacto ambiental: 1 . Aeropuertos. Madrid: DGMA, 1998.

OLIVEIRA, G.A. Método estatístico no auxílio à previsão de nevoeiro para o Aeroporto de Guarulhos. Florianópolis, 2002. Dissertação (Mestrado em Engenharia de Produção) Universidade Federal de Santa Catarina. 
VILLELA, R.J. Meteorologia aeroportuária da Ilha da Madeira. São Paulo, 1984.

Dissertação (Mestrado em Meteorologia) - Instituto Astronômico e Geofísico da Universidade de São Paulo.

\section{Agradecimentos}

Ao Sr. Gustavo Kaufmann pela cessão da foto utilizada neste artigo e ao amigo Denis Dorighello Tomás pela leitura e sugestões dos originais do trabalho. 